VOLUME 18 NOMOR 3, JULI 2019

\title{
USAHA MANISAN ANEKA RASA MELALUI PEMANFAATAN KULIT JERUK PAMELO DI DESA PADANGLAMPE KABUPATEN PANGKEP
}

\author{
M Fadhil $^{1}$ dan M Ashoer ${ }^{2}$
}

\begin{abstract}
ABSTRAK
Desa Padanglampe merupakan salah satu desa yang berada di Kecamatan Marang-Pangkep. Desa Padanglampe memiliki potensi yang sangat besar di bidang perkebunan, khususnya perkebunan jeruk pamelo. Kulit jeruk pamelo di desa Padanglampe biasanya dibuang oleh petani setempat karena dianggap sebagai sampah dan tidak memiliki nilai tambah ekonomis. Berbagai permasalahan mulai mengemuka ketika sampah jeruk pamelo yang telah dikonsumsi berpotensi menganggu masyarakat sekitar. Namun, ternyata kulit jeruk pamelo sebagai bahan limbah dapat dimanfaatkan dan diolah menjadi sebuah makanan yang tentunya setelah melalui proses dan perlakuan tertentu. Keterbatasan pengetahuan dan pengalaman masyarakat terutama petani jeruk pamelo di desa Padanglampe menjadi satu-satunya akar permasalahan dari terbuangnya potensi bisnis pengolahan limbah kulit jeruk pamelo. Oleh karena itu, dengan mendaur ulang limbah yang seharusnya dibuang menjadi suatu produk yang lebih berguna dan mempunyai nilai lebih menjadi kebutuhan sebagai salah satu alternatif usaha di tengah-tengah kelesuan berbisnis masyarakat desa Padanglampe. Selain itu, pengolahan ini juga dapat meningkatkan pendapatan asli masyarakat. Adapun luaran yang diharapkan dari program ini adalah berupa usaha produksi manisan aneka rasa melalui pengolahan kulit jeruk pamelo yang siap untuk dipasarkan.
\end{abstract}

\section{Kata Kunci : Jeruk Pamelo, Pengolahan Limbah Perkebunan}

\begin{abstract}
Padanglampe Village is one of the villages located in Marang-Pangkep District. Padanglampe village has huge potential in the plantation sector, especially the Pamelo orange plantation. Pamelo orange peel in Padanglampe village is usually discarded by local farmers because it is considered as garbage and has no economic added value. Various problems began to emerge when the pamelo orange waste that was consumed had the potential to disturb the surrounding community. However, it turns out that Pamelo orange peel as a waste material can be utilized and processed into a food which of course after going through certain processes and treatments. The limited knowledge and experience of the community, especially Pamelo orange farmers in the village of Padanglampe, is the only root cause of the waste in the waste processing business potential. Therefore, by recycling waste that should be disposed of into a product that is more useful and has more value, it becomes a necessity as an alternative to business amidst the sluggish business of the people of Padanglampe village. In addition, this processing can also increase the people's original income. The expected outcome of this program is in the form of a business of producing various flavors through the processing of orange peel pellets that are ready to be marketed.
\end{abstract}

Keywords: Pamelo Oranges, Plantation Waste Management

${ }^{1}$ Dosen Program Studi Manajemen FEB Universitas Muslim Indonesia, Muhammad.fadhil@umi.ac.id

${ }^{2}$ Dosen Program Studi Manajemen FEB Universitas Muslim Indonesia, azhurmuhammad@gmail.com 


\section{PENDAHULUAN}

Indonesia terkenal dengan tanahnya yang subur. Bahkan untuk satu jenis buah seperti jeruk sekalipun, orang bisa menyebutnya dengan banyak nama. Jika Provinsi Kalimantan Barat terkenal dengan jeruk pontianak dan Jawa Barat terkenal pula dengan jenis jeruk garut, di Sulawesi Selatan, khususnya Kabupaten Pangkep, Desa Padanglampe dikenal sebagai salah satu daerah penghasil Jeruk Pamelo (jeruk bali) di Indonesia. Padanglampe adalah salah satu desa di Kecamatan Ma'rang, Kabupaten Pangkajene dan Kepulauan, Sulawesi Selatan, Indonesia. Berdasarkan potensi yang dilihat pada luas komoditi yang diusahakan, Desa dengan Potensi Lahan Pertanian Jeruk Pamelo terbesar di Sulawesi Selatan. Jeruk Pamelo sebagai komoditi unggulan memiliki potensi kesesuaian lahan optimal pada Kecamatan Ma'rang dan Labakkang. Luas panen keduanya mencapai $88 \%$ dari total yang ada di Kabupaten Pangkep Rata-rata panen 400 pohon per hektar dengan rata-rata per pohon menghasilkan sekitar 60 buah jeruk dalam setiap hektar saja potensi omzet yang bisa diraup mencapai Rp 60 juta. Omzet itu diperoleh dengan mengasumsikan harga jual terendah sekitar Rp 2.500 per buah jeruk. Sampai saat ini menurut data dinas pertanian setempat, pemasaran jeruk pamelo masih melalui para pengepul lokal perorangan dan belum dilakukan secara profesional.

Kulit jeruk pamelo di desa Padanglampe biasanya dibuang oleh petani setempat karena dianggap sebagai sampah dan tidak memiliki nilai tambah ekonomis. Berbagai permasalahan mulai mengemuka ketika sampah jeruk pamelo yang telah dikonsumsi berpotensi menganggu masyarakat sekitar. Namun, ternyata kulit jeruk pamelo sebagai Bahan limbah dapat dimanfaatkan dan diolah menjadi sebuah makanan yang tentunya setelah melalui proses dan perlakuan tertentu. Beberapa penelitian terdahulu telah membuktikan berbagai macam hasil olahan dari kulit jeruk pamelo, mulai dari manisan aneka rasa (Askari, 2004) dan selai (Efendi dkk, 2008). Keterbatasan pengetahuan dan pengalaman masyarakat terutama petani jeruk pamelo di desa Padanglampe menjadi satu-satunya akar permasalahan dari terbuangnya potensi bisnis pengolahan limbah kulit jeruk pamelo. Oleh karena itu, dengan mendaur ulang limbah yang seharusnya dibuang menjadi suatu produk yang lebih berguna dan mempunyai nilai lebih menjadi kebutuhan sebagai salah satu alternatif usaha di tengah-tengah kelesuan berbisnis masyarakat desa Padanglampe. Selain itu, pengolahan ini juga dapat meningkatkan pendapatan asli masyarakat. Pengolahan kulit jeruk pamelo menjadi manisan adalah satu terobosan baru yang mungkin akan diminati oleh masyarakat karena selain murah dan sehat, cemilan ini juga mengandung zat tinggi dan belum ada sebelumnya sehingga masyarakat cenderung tertarik untuk mencobanya. Peluang usaha ini diharapkan dapat memberikan alternatif usaha bagi para masyarakat desa, serta secara tidak langsung akan meningkatkan taraf hidup ekonomi masyarakat. 


\section{METODE PELAKSANAAN}

Metode yang diterapkan dalam kegiatan pengabdian ini adalah metode partisipatif melalui pemberian penyuluhan dan sosialisasi pengolahan jeruk bali menjadi manisan aneka rasa kepada calon wirausahawan baru di desa Padanglampe, Kabupaten Pangkep. Metode pelaksanaan terdiri atas 3 (tahap) tahap yaitu penyuluhan perencanaan bisnis, pelatihan proses pengolahan jeruk bali, dan evaluasi. Metode pertama adalah perencanaan bisnis dan strategi pemasaran produk yang dilakukan dengan beberapa tahap yaitu memberikan kemasan ekonomis dengan harga yang lebih terjangkau, menjual manisan dengan harga yang lebih murah dari yang ada dipasar. Dengan tujuan meningkatkan jumlah pelanggan/konsumen, walaupun keuntungan yang didapat kurang maksimal. Metode pemasaran selanjutnya adalah dengan mengkhususkan pasar yang dituju, yaitu pada tempattempat wisata udan pada umumnya toko-toko makanan ringan. Dan untuk meramalkan keuntungan dilakukan dengan melihat penjualan dan pesaing di pasar. Metode pemasaran yang terakhir adalah dengan melakukan inovasi-inovasi baru agar konsumen tidak bosan dengan produk kita.

Selanjutnya, metode kedua ialah pelatihan dan pendampingan yang dimulai dari penyiapan bahan baku, pengupasan dan pengirisan kulit keruk pamelo, perendaman, perebusan, pengovenan, dan pengemasan manisan kulit keruk pamelo. Secara rinci, rencana proses produksi manisan aneka rasa terdiri dari 5 (lima) tahap, yaitu;

- Tahap pertama, tahap ini adalah penyiapan bahan baku, bahan baku yang digunakan adalah jeruk Pamelo yang masih muda karena kulit jeruknya lebih tebal. Bahan baku langsung dipetik dari kebun jeruk, sehingga kesegaran dan mutunya terjamin.

- Tahap kedua, pengupasan dan pengirisan kulit jeruk,pada tahap ini kulit jeruk bagian dari luar harus dikupas kemudian kulit jeruk bagian dalam dipotong kecil-kecil.

- Tahap ketiga, perendaman kulit jeruk, kulit jeruk yang telah dipotong tersebut kemudian dimasukkan dalam bak dan direndam dengan menggunakan air garam selama 1 hari dengan takaran 2 bungkus garam dapur untuk $5 \mathrm{Kg}$ kulit jeruk. Setelah perendaman kulit jeruk dicuci bersih hingga rasa pahit kulit jeruk hilang.

- Tahap ke empat, perebusan kulit jeruk, kulit jeruk yang telah dicuci direbus 3 kali. Perebusan pertama dilakukan dengan menggunakan air setengah panci, gula $1 \mathrm{Kg}, 1$ sdm citrun untuk $3 \mathrm{Kg}$ kulit jeruk, setelah mendidih didiamkan 1 malam. Perebusan ke dua dilakukan dengan menambahkan gula dan aroma makanan, saat perebusan kedua ini manisan harus dibagi menjadi 5 panci, karena setiap panci akan diberi aroma yang berbeda, yaitu aroma gula asli, aroma coklat, aroma susu, aroma strawberry, dan aroma melon setelah mendidih didiamkan 1 malam. Perebusan ke tiga dilakukan sampai air dalam panci habis setelah itu di- diamkan selama 1 malam sebelum proses selanjutnya. Tujuan didiamkannya kulit jeruk selama 1 malam adalah supaya air gula dan aromanya meresap ke dalam manisan kulit jeruk. Tahap ke lima adalah pemanggangan atau pengovenan manisan kulit jeruk. Setelah dilakukan perebusan proses selanjutnya adalah pe- manggangan. Pemanggangan dilakukan agar manisan terlihat kering dan agar rasanya lebih nikmat. Manisan kulit jeruk yang telah direbus tadi dimasukkan ke dalam alat pemanggang, selanjutnya kulit jeruk tersebut dipanggang selama kurang lebih 6-8jam dengan suhu rata-rata sekitar $50^{\circ} \mathrm{C}$. Setelah dilakukan pemanggangan manisan tersebut didiamkan 1 malam agar uap panasnya hilang.

- Tahap kelima yaitu tahap pengemasan manisan kulit jeruk, setelah pemanggangan 
manisan kulit jeruk pun siap dikemas. Dalam pengemasan ini ada dua macam kemasan, yaitu kemasan pertama adalah kemasan plastik mika dengan isi bersih manisan 80 gram, yang rencana akan dijual dengan harga Rp. 2.000,00 per bungkusnya. Kemasan kedua adalah kemasan kotak kertas, dengan isi bersih 150 gram, yang nantinya dijual dengan harga Rp. 3.500,00 per bungkusnya. Selain itu masing-masing kemasan (mika dan kotak) terdiri dari 6 pilihan rasa yaitu rasa jeruk asli, rasa cokelat, rasa susu, rasa strawbery dan rasa melon. Tujuan utama dari penganekaragaman produk ini adalah agar konsumen tidak bosan dengan rasa yang disajikan dan kemasan yang disajikan. Selain itu tujuan yang lainnya adalah karena keadaan ekonomi konsumen, bagi konsumen yang berdaya beli rendah telah disediakan kemasan ekonomi dengan harga Rp. 2000,00 per bungkusnya. Sedangkan merek awal yang digunakan dalam kemasan manisan kulit jeruk ini adalah "MANISAN KHAS PADANGLAMPE". Tujuan utama dari penggunaan merk ini adalah agar konsumen mengetahui asal dari produk manisan ini.

\section{HASIL dan PEMBAHASAN}

\subsection{Pembahasan}

- Sosialisasi pengolahan produk (Manisan Aneka Rasa) yang sehat, higienis dan berkualitas dengan harga yang terjangkau.

- Strategi merek produk (nama, logo, bentuk, pengemasan, dan harga) yang menarik dan kreatif serta sesuai dengan ciri khas desa Padanglampe.

- Strategi segmentasi pasar (segmentation), penentuan sasaran/ target (targeting), dan pemosisian produk (positioning) untuk dapat menjangkau konsumen yang tepat.

\subsection{Sasaran Kegiatan}

- Masyarakat desa yang akan disiapkan untuk menjadi pelaku usaha baru manisan aneka rasa melalui pengolahan kulit jeruk pamelo di desa Padanglampe.

\subsection{Hasil}

Output yang diharapkan dari program ini adalah berupa usaha produksi manisan aneka rasa melalui pengolahan kulit jeruk pamelo yang siap untuk dipasarkan

\section{SIMPULAN DAN SARAN}

Berdasarkan pembahasan diatas maka simpulan yang dapat digambarkan mengenai kegiatan program IbM ini yaitu hasil olahan kulit jeruk pamelo dengan rencana merek "MANISAN PADLAM" yang akan diproduksi dan dipasarkan diharapkan dapat diterima oleh seluruh kalangan masyarakat desa, maka sebaiknya harus mengetahui dan melakukan beberapa hal untuk penyempurnaan, yaitu:

- Memberikan pemahaman akan pentingnya kewirausahaan

- Membuat produk MANISAN PADLAM yang berkualitas dan bermanfaat dengan harga yang mampu bersaing.

- Membuat desain cover produk yang inovatif dan kreatif serta mematok harga yang terjangkau.

- Membuat produk yang bisa tahan lama (paling lama 3 bulan).

- Menentukan wilayah pemasaran yang strategis dan menguntungkan. 
Adapun saran dari kegiatan ini adalah :

- Masih perlu mengadakan peralatan produk olahan yang memadai untuk meningkatkan produksi.

- Diperlukan media yang bisa mempromosikan produk kue kering agar dapat memperluas jaringan pemasaran produk.

\section{DAFTAR PUSTAKA}

Arisandy, Bayu. 2005. Analisis Product Positioning serta preferensi Konsumen nata de coco pada PT. FITS Mandiri di Bogor. Skripsi. Fakultas Pertanian, Institut Pertanian Bogor.

Guiltinan, J.P and Gordon W. Paul. 1992. Strategi dan Program Manajemen Pemasaran. Terjemahan. Agus Maulana. Erlangga, Jakarta.

Kotler P, \& Keller K. L, 2009, Marketing Management (13th,ed). New York : Prentice Hall.

Rangkuti, F. 2000. Analisis SWOT Teknik Membedah Kasus Bisnis. PT Gramedia Pustaka Utama, Jakarta.

Shrivastava, P. 1994. Strategic Management Concept and Practices. South Western Publishing Co, Ohio.

Toyne, B. And Peter G.P Walters. 1989. Global Marketing Management a Strategic Perspective. Second Edition. Allyn and Boston, Massachusetts.

Urban, G.L and Steven H. Star. 1991. Advance Marketing Strategy : Phenomena, Analysis and Decision. Prentice Hall, New Jersey.

\section{Lampiran - Dokumentasi Kegiatan}
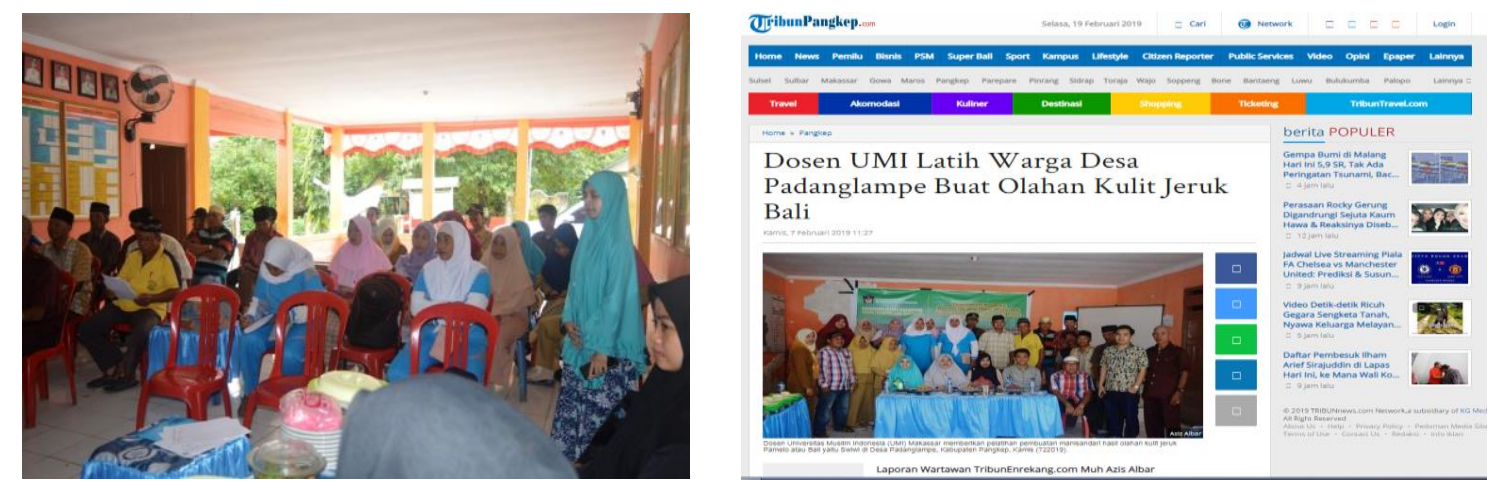

Link Berita Pengabdian yang dimuat oleh media Tribun Pangkep.

http://makassar.tribunnews.com/2019/02/07/dosen-umi-latih-warga-desa-padanglampe-buatolahan-kulit-jeruk-bali 